Article

\title{
Mathematical Modeling Analysis and Optimization of Key Design Parameters of Proton-Conductive Solid Oxide Fuel Cells
}

\author{
Hong Liu, Zoheb Akhtar, Peiwen Li * and Kai Wang \\ Department of Aerospace and Mechanical Engineering, The University of Arizona, Tucson, \\ AZ 85721, USA; E-Mails: liuhong@email.arizona.edu (H.L.); zakhtar@email.arizona.edu (Z.A.); \\ kaiwang@email.arizona.edu (K.W.) \\ * Author to whom correspondence should be addressed; E-Mail: peiwen@email.arizona.edu; \\ Tel.: +1-520-626-7789.
}

Received: 19 November 2013; in revised form: 20 December 2013 / Accepted: 24 December 2013 / Published: 7 January 2014

\begin{abstract}
A proton-conductive solid oxide fuel cell (H-SOFC) has the advantage of operating at higher temperatures than a PEM fuel cell, but at lower temperatures than a SOFC. This study proposes a mathematical model for an H-SOFC in order to simulate the performance and optimize the flow channel designs. The model analyzes the average mass transfer and species' concentrations in flow channels, which allows the determination of an average concentration polarization in anode and cathode gas channels, the proton conductivity of electrolyte membranes, as well as the activation polarization. An electrical circuit for the current and proton conduction is applied to analyze the ohmic losses from an anode current collector to a cathode current collector. The model uses relatively less amount of computational time to find the V-I curve of the fuel cell, and thus it can be applied to compute a large amount of cases with different flow channel dimensions and operating parameters for optimization. The modeling simulation results agreed satisfactorily with the experimental results from literature. Simulation results showed that a relatively small total width of flow channel and rib, together with a small ratio of the rib's width versus the total width, are preferable for obtaining high power densities and thus high efficiency.
\end{abstract}

Keywords: proton-conductive SOFC; mathematical model; optimization of gas channels

\section{Nomenclature:}

$A \quad$ Mass transfer area of cross section $\left(\mathrm{m}^{2}\right)$

C Species molar concentration $\left(\mathrm{mol} / \mathrm{m}^{3}\right)$ 




Greek Symbols

$\begin{array}{ll}\tau & \text { Tortuosity } \\ \varepsilon & \text { Porosity } \\ \delta & \text { Electrode thickness (m) } \\ \alpha & \text { Transfer coefficient }\end{array}$

Subscripts and Superscripts

$\begin{array}{ll}\text { int } & \text { Interface (electrode-functional layer) } \\ \text { conc } & \text { Concentration polarization } \\ c & \text { Cathode } \\ a & \text { Anode } \\ \text { af } & \text { Anode functional layer } \\ c f & \text { Cathode functional layer } \\ \mathrm{H}_{2} & \text { Hydrogen } \\ \mathrm{O}_{2} & \text { Oxygen } \\ \mathrm{N}_{2} & \text { Nitrogen }\end{array}$


$S \quad$ Surface

$\infty \quad$ Bulk flow

\section{Introduction}

Having an electrolyte conductive to oxide ions, a solid oxide fuel cell (O-SOFC) works at relatively high operating temperatures, which helps to maintain a low activation polarization and eliminate the use of expensive catalysts in a fuel cell [1]. However, high operating temperatures also result in disadvantages including potential thermal fatigue/failure of the cell material and gas sealing, as well as the thermal stress in the ceramic cell components [2]. With the solid oxide electrolyte being conductive to protons, a proton-conductive solid oxide fuel cell (H-SOFC) works at a relatively lower temperature [3] than a regular SOFC. A lower operation temperature helps to alleviate the problems of thermal stress and thermal expansion mismatch related to high operating temperatures in a regular SOFC. An H-SOFC also allows more utilization of the fuel $\left(\mathrm{H}_{2}\right)$ and thus a better efficiency than a regular SOFC [4].

A number of research efforts have been devoted to experimental studies on proton conductive solid oxide fuel cells. Some of them focused on property of materials used for H-SOFC. For the key component material of an H-SOFC, Zhao et al. studied the performance of H-SOFC using $\mathrm{BaCe}_{0.7} \mathrm{In}_{0.3-\mathrm{x}} \mathrm{Y}_{\mathrm{x}} \mathrm{O}_{3-\delta}$ as the electrolyte material [5]. Ling et al. studied the fuel cell performance using a stable $\mathrm{La}_{2} \mathrm{Ce}_{2} \mathrm{O}_{7}$ as the electrolyte material [6]. Guo et al. studied the performance of a carbon dioxide-tolerant proton-conducting solid oxide fuel cell with a dual-layer electrolyte [7]. H-SOFC was also tested using $\mathrm{BaZr}_{0.8} \mathrm{In}_{0.2} \mathrm{O}_{3-\delta}$ as the proton-conductive electrolyte [8]. For electrode materials, Lin et al. evaluated the performance of $\mathrm{H}-\mathrm{SOFC}$ using $\mathrm{BaCo}_{0.7} \mathrm{Fe}_{0.2} \mathrm{Nb}_{0.1} \mathrm{O}_{3-\delta}$ (BCFN) as the cathode material [9]. Deng et al. investigated fuel cell performance using a cathode made of the material of $\mathrm{PrBa}_{0.5} \mathrm{Sr}_{0.5} \mathrm{Co}_{2} \mathrm{O}_{5-\delta}[10]$. Zhao et al. studied the performance of a cobalt-free proton-conductive oxide fuel cell performance using $\mathrm{Ba}_{0.5} \mathrm{Sr}_{0.5} \mathrm{Fe}_{0.8} \mathrm{Cu}_{0.2} \mathrm{O}_{3-\delta}$ as cathode material [11]. For fabrication related issues, Tsai et al. studied the tortuosity in electrodes materials in an anode-supported H-SOFC [12].

While the materials of the H-SOFC component are very important, a good design and management of the flow field is also very helpful to a better performance of the fuel cells. The current work presents studies and design optimization of a H-SOFC via modeling and simulation analysis. The modeling will give an easy-to-approach and comprehensive analysis to the mass transfer, activation and ohmic polarizations, and can predict the fuel cell performance and thus optimize the flow channel designs [13]. The simulation results are to be compared with the experimental results obtained from literature to validate the model. The power density and voltage output due to the optimization of the dimensions of flow channels and ribs will be presented.

\section{Basic Aspects of an H-SOFC}

A proton conducting solid oxide fuel cell consists of a metal oxide electrolyte sandwiched between two electrodes. Fuel is supplied on the anode side which is oxidized into protons in an electrochemical reaction as: 


$$
H_{2} \rightarrow 2 H^{+}+2 e^{-}
$$

This produces electrons which move towards cathode via an external circuit driven by the potential difference between the two electrodes. The fuel consumption leads to concentration gradient of hydrogen (if fuel is a mixture) in anode and therefore feed to the anode-electrolyte interface by permeation [14]. In cathode, air is supplied, which offers oxygen to react with the receiving electrons and protons from anode to form water from the following electrochemical reaction:

$$
\frac{1}{2} \mathrm{O}_{2}+2 \mathrm{H}^{+}+2 e^{-} \rightarrow \mathrm{H}_{2} \mathrm{O}
$$

The anode material and catalyst are required to be highly active to improve the H-SOFC performance. These days, mixtures of nickel oxide and electrolyte are used as anode support materials [15]. Nickel behaves like a catalyst which increases the rate of chemical reaction and oxidizes the fuel at the interface. The anode reaction occurs at the interface of anode and electrolyte. Together with the reactant phase, the anode and electrolyte forms the so-called triple phase boundary. Mixtures of $\mathrm{NiO}$ and electrolyte increase the triple phase boundary. Electrolyte material behaves like a proton conductor which conducts protons and transfers it across electrolyte layer. Good proton conductivity is important to the increase of the rate of the overall reaction [16]. The electrolyte must be as thin as possible and have low activation energy. The perovskite structured compound $\left(\mathrm{ABO}_{3}\right.$ specially $\left.\mathrm{AZrO}_{3}\right)$ family are considered especially good electrolyte materials. An ideal cathode material must be chemically non-reactive with the electrolyte. A cathode material must be porous with high oxygen permeability. Due to these reasons novel perovskite oxide materials are chosen as cathode. Recently, $\mathrm{Ba}_{0.5} \mathrm{Sr}_{0.5} \mathrm{Zn}_{0.2} \mathrm{Fe}_{0.8} \mathrm{O}_{3-\delta}$ (BSZF) has been developed as a novel cobalt free oxygen permeable membrane with high permeation behavior and good chemical stability at high temperatures [17].

Different from an oxide-ion conductive SOFC, H-SOFCs have the electromotive force expressed as:

$$
E=\frac{-\Delta G^{o}}{2 F}+\frac{R T}{2 F} \ln \left[\left(\frac{P_{\mathrm{H}_{2}}}{P^{o}}\right)_{\text {anode }}\left(\frac{P_{\mathrm{O}_{2}}}{P^{o}}\right)_{\text {cathode }}^{0.5} /\left(\frac{P_{\mathrm{H}_{2} \mathrm{O}}}{P^{o}}\right)_{\text {cathode }}\right]
$$

Due to its high operation temperature, the water in H-SOFC is in vapor state and is assumed as an ideal gas, the same as other gas species.

\section{Numerical Modeling to H-SOFC}

Figure 1 shows the schematic of the typical elements/components of an H-SOFC, which includes the electrolyte, electrode components, flow channels, as well as the flow channel walls also acting also as local current collectors. $\mathrm{BaCe}_{0.9} \mathrm{Y}_{0.1} \mathrm{O}_{2.95}$ (BCY) and $\mathrm{BaCe}_{0.5} \mathrm{Zr}_{0.3} \mathrm{Y}_{0.16} \mathrm{Zn}_{0.04} \mathrm{O}_{3-\delta}$ (BCZYZn) are used as electrolytes for the current mathematic model [15,17]. The anode material is $\mathrm{NiO}$ which has a substrate of NiO-BCY and NiO-BCZYZn. The cathode materials are $\mathrm{Ba}_{0.5} \mathrm{Sr}_{0.5} \mathrm{Zn}_{0.2} \mathrm{Fe}_{0.8} \mathrm{O}_{3-\delta}(\mathrm{BSZF})$ and $\mathrm{Ba}_{0.5} \mathrm{Sr}_{0.5} \mathrm{Co}_{0.8} \mathrm{Fe}_{0.2} \mathrm{O}_{3-\delta}$ (BSCF). The electrode and electrolyte materials properties used for the simulation are presented in Tables 1 and 2. The contact resistances between current collector and electrodes vary with operation temperatures, which are given in Table 3 . Fuel was supplied on the anode side, and cathode was fed with air for the needed oxygen. The utilization of fuel and oxygen are $85 \%$ and $50 \%$, respectively, and a unit length of $1.0 \mathrm{~m}$ of the channel length (normal to the paper in Figure 1 ) is 
considered in the modeling. Setting the utilization percentage of fuel and oxygen being constant, the flow rates of fuel and air vary with the current density.

Figure 1. Schematic of H-SOFC showing only one pair of flow channels on two sides of the MEA.

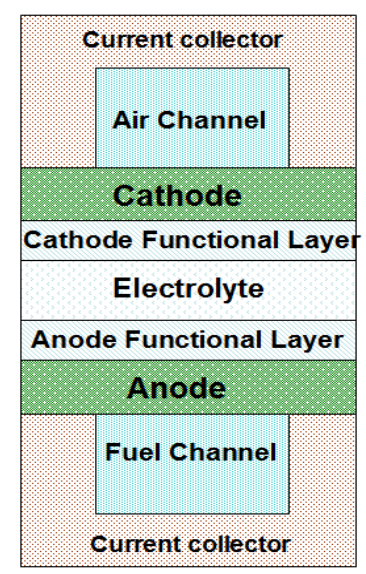

Table 1. Physical properties of the electrodes materials.

\begin{tabular}{cccccc}
\hline Properties & Anode & Cathode & Anode functional layer & Cathode functional layer \\
\hline Pore Radius $\times 10^{-6}(\mathrm{~m})$ & 2 & 2 & 2 & 2 \\
Porosity & 0.48 & 0.48 & 0.48 & 0.48 \\
Tortuosity & 3 & 3 & 3 & 3 \\
Thickness $\times 10^{-4}(\mathrm{~m})$ & 6 & 0.2 & 0.2 & 0.1 \\
\hline
\end{tabular}

Table 2. Proton conductivity of the electrolyte at different operating temperatures.

\begin{tabular}{cccccc}
\hline Temperature $\left({ }^{\circ} \mathbf{C}\right)$ & $\mathbf{5 0 0}$ & $\mathbf{5 5 0}$ & $\mathbf{6 0 0}$ & $\mathbf{6 5 0}$ & $\mathbf{7 0 0}$ \\
\hline Proton conductivity $(\mathrm{S} / \mathrm{m})$ & 0.6 & 0.77 & 0.95 & 1.12 & 1.38 \\
\hline
\end{tabular}

Note: Electrolyte has a thickness of $5 \times 10^{-5}(\mathrm{~m})$.

Table 3. Contact resistivity between current collector and electrodes at different operation temperature [17].

\begin{tabular}{cccccc}
\hline Temperature $\left({ }^{\circ} \mathbf{C}\right)$ & $\mathbf{5 0 0}$ & $\mathbf{5 5 0}$ & $\mathbf{6 0 0}$ & $\mathbf{6 5 0}$ & $\mathbf{7 0 0}$ \\
\hline $\begin{array}{c}\text { Contact Resistivity } \\
\left(\times 10^{-7} \Omega / \mathrm{m}^{2}\right)\end{array}$ & 3.8 & 1.73 & 0.95 & 0.6 & 0.2 \\
\hline
\end{tabular}

To obtain the electromotive force, the partial pressures of species during an electrochemical reaction are needed. The partial pressure of a species is proportional to its molar fraction in a mixture. Therefore, the mass transfer processes of species from bulk flow to the reaction site (the electrode and electrolyte interface) have to be analyzed. 


\subsection{Mass Transfer Analysis}

\subsubsection{Anode Side Mass Transfer Analysis}

The convective mass transfer flow rate of hydrogen from bulk flow to the surface of anode is expressed in Equation (4). The consumed hydrogen flow rate $\dot{n}$ equals to the current divided by $2 \mathrm{~F}$, where $\mathrm{F}$ is the Faraday constant.

$$
\dot{n}=A h_{H_{2}}\left(C_{\infty}^{H_{2}}-C_{S}^{H_{2}}\right)
$$

where $h_{H 2}$ is convective mass transfer coefficient, $C_{\infty}^{H_{2}}$ is the average molar concentration of hydrogen in the bulk flow, $C_{S}^{H_{2}}$ is the average molar concentration of hydrogen at the anode surface, and $A$ is the mass transfer area of the electrode in exposure to the flow channels.

The mass diffusion for hydrogen and vapor in porous electrodes are analyzed by calculating the mass transfer flow rate as given in Equations (5) and (6). For all the analyses, the mass fluxes from surfaces toward the bulk flow are designated to be positive.

$$
\begin{gathered}
J_{H 2}=-D_{H 2(e f f)} \nabla C^{H 2}+C^{H 2} v^{a} \\
J_{H 2 O}=-D_{H 2 O(e f f)} \nabla C^{H 2 O}+C^{H 2 O} v^{a}
\end{gathered}
$$

where $v$ is an anode diffusion velocity due to the mass diffusion of hydrogen, $C^{H 2}$ and $C^{H 2 O}$ are the average molar concentration of hydrogen and water in the porous layer, respectively.

In the fuel channel, the hydrogen is consumed and protons conduct through the electrolyte to form water with oxygen on the cathode side. Therefore, there is no water vapor flux on anode, which gives $J_{H 2 O}=0$. The effective diffusivity of hydrogen-water system comprises of Knudsen and ordinary diffusion.

$$
\begin{gathered}
\frac{1}{D_{H 2(e f f)}}=\frac{\tau}{\varepsilon}\left(\frac{1}{D_{H 2, k}}+\frac{1}{D_{H 2-H 2 O}}\right) \\
\frac{1}{D_{H 2 O(e f f)}}=\frac{\tau}{\varepsilon}\left(\frac{1}{D_{H 2 O, k}}+\frac{1}{D_{H 2 O-H 2}}\right)
\end{gathered}
$$

where $\tau$ and $\varepsilon$ represent the tortuosity and porosity of porous electrode, respectively. Knudsen diffusivities $D_{H 2, k}$ and $D_{H 2 O, k}$ are calculated using $D_{i, k}=97 r_{e} \sqrt{\frac{T}{M_{i}}}$, where $r_{e}$ is the average pore radius of porous electrode. $D_{H 2-H 2 O}$ is the binary diffusivity, which is obtained through the following equation [18],

$$
D_{i-j}=\frac{0.0101 T^{1.75}\left(\frac{1}{M_{i}}+\frac{1}{M_{j}}\right)^{0.5}}{P\left[V_{i}^{1 / 3}+V_{j}^{1 / 3}\right]^{2}}
$$

where $\mathrm{V}_{\mathrm{H} 2}, \mathrm{~V}_{\mathrm{N} 2}, \mathrm{~V}_{\mathrm{O} 2}$ and $\mathrm{V}_{\mathrm{H} 2 \mathrm{O}}$ are $7.07,17.9,16.6$ and 12.7, respectively [18].

The total wall flow velocity due to mass transfer is directly related to summation of mass flux of all species and the total density at wall. Therefore, there is. 


$$
v^{a}=\frac{J_{H_{2}} M_{H_{2}}}{C^{H_{2}} M_{H_{2}}+C^{H_{2} O} M_{H_{2} O}}
$$

This is a basic equation describing mass transfer boundary conditions [19]. Substituting diffusion velocity $v^{a}$ back to Equations (5) and (6) and introducing the new effective diffusivities for hydrogen and vapor as given by Equations (11) and (12), we could obtain compact expression for mass flux as given by Equations (13) and (14).

$$
\begin{gathered}
\mathrm{D}_{\mathrm{a}_{-} \mathrm{H}_{2} \text { (eff) }}=\mathrm{D}_{\mathrm{H}_{2} \text { (eff) }} \frac{\mathrm{C}^{\mathrm{H}_{2} \mathrm{O}} \mathrm{M}_{\mathrm{H}_{2} \mathrm{O}}+\mathrm{C}^{\mathrm{H}_{2}} \mathrm{M}_{\mathrm{H}_{2}}}{\mathrm{C}^{\mathrm{H}_{2} \mathrm{O}} \mathrm{M}_{\mathrm{H}_{2} \mathrm{O}}} \\
\mathrm{D}_{\mathrm{a}_{-} \mathrm{H}_{2} \mathrm{O} \text { (eff) }}=\mathrm{D}_{\mathrm{H}_{2} \mathrm{O} \text { (eff) }} \frac{\mathrm{C}^{\mathrm{H}_{2}} \mathrm{M}_{\mathrm{H}_{2}}+\mathrm{C}^{\mathrm{H}_{2} \mathrm{O}} \mathrm{M}_{\mathrm{H}_{2} \mathrm{O}}}{\mathrm{C}^{\mathrm{H}_{2} \mathrm{O}} \mathrm{M}_{\mathrm{H}_{2}}} \\
\mathrm{~J}_{\mathrm{H}_{2}}=-\mathrm{D}_{\mathrm{a}_{-} \mathrm{H}_{2} \text { (eff) }} \nabla \mathrm{C}^{\mathrm{H}_{2}} \\
\mathrm{~J}_{\mathrm{H}_{2}}=\mathrm{D}_{\mathrm{a}_{-} \mathrm{H}_{2} \mathrm{O}(\text { eff })} \nabla \mathrm{C}^{\mathrm{H}_{2} \mathrm{O}}
\end{gathered}
$$

Given the molar consumption fluxes of hydrogen and water to left-hand sides of the above equations and considering the hydrogen molar concentration difference from the bulk flow to the anode surface, the concentration difference of hydrogen through the porous layer is given in Equation (15). Correspondingly, the concentration difference of water is given in Equation (16).

$$
\begin{gathered}
\frac{i}{2 F}\left(\frac{1}{h_{H 2}}+\frac{\delta_{a}}{\left.D_{a_{-} H 2(e f f)}\right)}\right)=C_{\infty}^{H 2}-C_{\mathrm{int}}^{H 2} \\
\frac{i}{2 F}\left(\frac{\delta_{a}}{D_{a_{-} H 2 O(e f f)}}\right)=C_{\mathrm{int}}^{H 2 O}-C_{\infty}^{H 2 O}
\end{gathered}
$$

To consider the mass diffusion resistance in anode functional layer, we can simply add the mass transfer resistance term of the functional layer, $\left(\frac{\delta_{a f}}{D_{a f_{-} H 2(e f f)}}\right)$, to the parenthesis on the left-hand side of Equations (15) and (16). Here $\delta_{a f}$ is the thickness of the anode functional layer. The equation for $D_{a f_{-} H 2(e f f)}$ is in the same form as that of Equation (11). However, the parameters used for calculating $D_{a f_{-} H 2(e f f)}$ are from anode functional layer. Equations for mass fluxes for water vapor in the functional layer are similar to those in the anode layer, which are not presented here.

From the above analysis, it is clear that with the given current density and the concentration of species in the bulk flow, one can obtain the species concentration at the anode/electrolyte interface.

\subsubsection{Cathode Side Mass Transfer Analysis}

On the cathode side, there are three species, $\mathrm{O}_{2}, \mathrm{~N}_{2}$ and $\mathrm{H}_{2} \mathrm{O}$ involved in the mass transfer. Similar to the anode side, the same analysis should be applied to the cathode side to find out the concentration of $\mathrm{O}_{2}, \mathrm{~N}_{2}$ and $\mathrm{H}_{2} \mathrm{O}$ at electrolyte/cathode interface. The molar consumption rate of $\mathrm{O}_{2}$ is known as the total current divided by $4 \mathrm{~F}$, where $\mathrm{F}$ is the Faraday's constant. Analogous to mass transfer, the mass transfer flux of oxygen from bulk flow to the cathode surface is similar to that of hydrogen at the anode side. 
The mass transfer of oxygen, nitrogen and water in porous cathode layer are described using the following equations.

$$
\begin{gathered}
J_{O 2}=-D_{O 2(\text { eff })} \nabla C^{O 2}+C^{O 2} v^{c} \\
J_{N 2}=-D_{N 2(\text { eff })} \nabla C^{N 2}+C^{N 2} v^{c} \\
J_{H 2 O}=-D_{H 2 O(\text { eff })} \nabla C^{H 2 O}+C^{H 2 O} v^{c}
\end{gathered}
$$

where $v^{c}$ is an overall cathode mass diffusion velocity due to all species' mass diffusion on cathode. The mass transfer fluxes of oxygen and water are related to the current densities of the fuel cell. Nitrogen is not involved in any reaction, which has a flux of zero. The total mass diffusion velocity $v^{c}$ is in the form of:

$$
v^{c}=\frac{J_{O 2} M_{O 2}+J_{H 2 O} M_{H 2 O}}{C^{O 2} M_{O 2}+C^{H 2 O} M_{H 2 O}+C^{N 2} M_{N 2}}
$$

The effective diffusivities of species in mixture are given in Equations (21)-(23).

$$
\begin{gathered}
\frac{1}{D_{O 2(e f f)}}=\frac{\tau}{\varepsilon}\left(\frac{1}{D_{O 2, k}}+\frac{1}{D_{O 2-M i x}}\right) \\
\frac{1}{D_{N 2(e f f)}}=\frac{\tau}{\varepsilon}\left(\frac{1}{D_{N 2, k}}+\frac{1}{D_{N 2-M i x}}\right) \\
\frac{1}{D_{H 2 O(e f f)}}=\frac{\tau}{\varepsilon}\left(\frac{1}{D_{H 2 O, k}}+\frac{1}{D_{H 2 O-M i x}}\right)
\end{gathered}
$$

The ordinary diffusivity of one species in a mixture of more than two species is given by Equation (24).

$$
D_{i-M i x}=\frac{1-X_{i}}{\sum_{j \neq i} \frac{X_{j}}{D_{i-j}}}
$$

Here, cathode side effective diffusivities for three of the species are given in Equations (25)-(27). These diffusivities are used for cathode species' mass transfer, given by Equations (28)-(30) after substituting cathode velocity to the mass flux equations.

$$
\begin{gathered}
\mathrm{D}_{\mathrm{c}_{-} \mathrm{O}_{2}(\text { eff })}=\mathrm{D}_{\mathrm{O}_{2} \text { (eff) }} \frac{\mathrm{C}^{\mathrm{O}_{2}} \mathrm{M}_{\mathrm{O}_{2}}+\mathrm{C}^{\mathrm{H}_{2} \mathrm{O}} \mathrm{M}_{\mathrm{H}_{2} \mathrm{O}}+\mathrm{C}^{\mathrm{N}_{2}} \mathrm{M}_{\mathrm{N}_{2}}}{\mathrm{C}^{\mathrm{H}_{2} \mathrm{O}} \mathrm{M}_{\mathrm{H}_{2} \mathrm{O}}+\mathrm{C}^{\mathrm{N}_{2}} \mathrm{M}_{\mathrm{N}_{2}}} \\
\mathrm{D}_{\mathrm{c}_{-} \mathrm{N}_{2} \text { (eff) }}=\mathrm{D}_{\mathrm{N}_{2} \text { (eff) }} \frac{\mathrm{C}^{\mathrm{O}_{2}} \mathrm{M}_{\mathrm{O}_{2}}+\mathrm{C}^{\mathrm{H}_{2} \mathrm{O}} \mathrm{M}_{\mathrm{H}_{2} \mathrm{O}}+\mathrm{C}^{\mathrm{N}_{2}} \mathrm{M}_{\mathrm{N}_{2}}}{\mathrm{C}^{\mathrm{N}_{2}}} \\
D_{c_{-} H_{2} O(e f f)}=D_{\mathrm{H}_{2} \mathrm{O}(e f f)} \frac{C^{\mathrm{O}_{2}} M_{\mathrm{O}_{2}}+C^{\mathrm{H}_{2} \mathrm{O}} M_{\mathrm{H}_{2} \mathrm{O}}+C^{\mathrm{N}_{2}} M_{\mathrm{N}_{2}}}{C^{\mathrm{O}_{2}} M_{\mathrm{O}_{2}}+C^{N_{2}} M_{N_{2}}} \\
{\left[\frac{\delta_{c}}{D_{c_{-} O 2(e f f)}}\left(-\frac{i}{2 F} \frac{C^{O 2} M_{\mathrm{H}_{2} O}}{C^{H 2 O} M_{\mathrm{H} 2 O}+C^{N 2} M_{N 2}}-\frac{i}{4 F}\right)-\frac{i}{4 F} \frac{1}{h_{O 2}}\right]=C_{\text {int }}^{O 2}-C_{\infty}^{O 2}}
\end{gathered}
$$




$$
\begin{gathered}
{\left[-\frac{\delta_{c}}{D_{c_{-} N 2(e f f)}}\left(\frac{i}{2 F} M_{H 2 O}-\frac{i}{4 F} M_{O 2}\right)\right]=C_{\mathrm{int}}^{N 2}-C_{\infty}^{N 2}} \\
{\left[\frac{\delta_{c}}{D_{c_{-} H 2 O(e f f)}}\left(\frac{i}{2 F}+\frac{i}{4 F} \frac{C^{H 2 O} M_{O 2}}{C^{O 2} M_{O 2}+C^{N 2} M_{N 2}}\right)+\frac{i}{2 F} \frac{1}{h_{H 2 O}}\right]=C_{\mathrm{int}}^{H 2 O_{-} c}-C_{\infty}^{H 2 O_{-} c}}
\end{gathered}
$$

To consider the oxygen mass diffusion resistance in cathode functional layer, a new term, $R_{c f l}$, given in Equation (31) is introduced as follows, which can be added to the left-hand side of Equation (28) for cathode functional layer.

$$
R_{c f l \_O 2}=\frac{\delta_{c f}}{D_{c f-O 2(e f f)}}\left(-\frac{i}{2 F} \frac{C^{O 2} M_{H 2 O}}{C^{N 2} M_{N 2}+C^{H 2 O} M_{H 2 O}}-\frac{i}{4 F}\right)
$$

where $\delta_{c f}$ is the thickness of the cathode functional layer. The equation for $D_{c f-O 2(e f f)}$ is of the same form of Equation (25), however, parameters for $D_{c f-O 2(e f f)}$ must be from the cathode functional layer. Similar process could be applied to solve for nitrogen and water on cathode side. The mass concentration for these species at the interface between electrolyte and functional layer could be solved using similar approach with consideration of a resistivity term of $R_{c f l} N 2$ and $R_{c f l}{ }_{2} O$. The resistivity terms for these two species are listed as follows, by Equations (32) and (33).

$$
\begin{gathered}
R_{c f l_{-} N 2}=\frac{\delta_{c f}}{D_{c f-N 2(e f f)}}\left(\frac{i}{4 F} M_{O 2}-\frac{i}{2 F} M_{H 2 O}\right) \\
R_{c f l_{-} H 2 O}=\frac{\delta_{c f}}{D_{c f-H 2 O(e f f)}}\left(\frac{i}{2 F}+\frac{C^{H 2 O} M_{O 2}}{C^{O 2} M_{O 2}+C^{N 2} M_{N 2}} \frac{i}{4 F}\right)
\end{gathered}
$$

From the above analysis, it is clear that at any given current density, the molar concentrations of all species at the electrode/electrolyte can be obtained. Finally, the partial pressures of all species are related to the molar concentration in the following forms:

$$
\begin{gathered}
P_{\mathrm{int}}^{H 2}=\frac{C_{\mathrm{int}}^{H 2}}{C_{\mathrm{int}}^{H 2}+C_{\mathrm{int}}^{H 2 O}} P_{\text {Anode }} \\
P_{\mathrm{int}}^{O 2}=\frac{C_{\mathrm{int}}^{O 2}}{C_{\mathrm{int}}^{O 2}+C_{\mathrm{int}}^{H 2 O_{-} c}+C_{\mathrm{int}}^{N 2}} P_{\text {Cathode }} \\
P_{\mathrm{int}}^{H 2 O_{-} c}=\frac{C_{\mathrm{int}}^{H 2 O}}{C_{\mathrm{int}}^{O 2}+C_{\mathrm{int}}^{H 2 O_{-}}+C_{\mathrm{int}}^{N 2}} P_{\text {Cathode }}
\end{gathered}
$$

\subsection{Irreversible Voltage/Potential Losses}

\subsubsection{Activation Polarization}

The activation polarization is given by the Butler-Volmer equation [20], as given in Equation (37), where $J_{\text {current }}$ is the current density, $J_{0}$ is the exchange current density, $\alpha$ is the transfer coefficient which is typically set as $0.5, z$ is the number of electrons passed through the external circuit for every mole of fuel oxidation. For H-SOFC, the value of $z$ is 2 . Therefore, the activation polarization could be expressed in terms of current density $J$, as shown in Equation (38). 


$$
\begin{gathered}
J_{- \text {current }}=J_{0}\left[\exp \left(\frac{\alpha z F \eta_{a c t}}{R T}\right)-\exp \left(-\frac{(1-\alpha) z F \eta_{a c t}}{R T}\right)\right] \\
\eta_{\text {act }, i}=\frac{R T}{F} \ln \left[\frac{J_{\text {current }}}{2 J_{0, i}}+\sqrt{\left(\frac{J_{\text {current }}}{2 J_{0, i}}\right)^{2}+1}\right](i=\mathrm{a}, \mathrm{c})
\end{gathered}
$$

The exchange current density is related to material property and operation conditions (porosity, pore size, temperature and pressure). According to literature [20], exchange current density for O-SOFC is expressed in terms of the effect of both micro structural properties and operating condition as given in Equations (39) and (40). In Equations (39) and (40), $E_{a c t, a}\left(=1.0 \times 10^{5} \mathrm{~J} / \mathrm{mol}\right)$ and $E_{a c t, c}\left(=1.2 \times 10^{5} \mathrm{~J} / \mathrm{mol}\right)$ are activation energy levels at anode and cathode, respectively; $Y$ is the ratio of grain contact neck to the grain size and $\mathrm{n}$ is the porosity of electrodes; $D_{p}$ and $D_{s}$ represent the pore size and grain size; $k_{a}$ and $k_{c}$ are adjustable coefficients, which are reported as $\mathrm{k}_{\mathrm{a}}$ of $6.634 \times 10^{-8}$ and $\mathrm{k}_{\mathrm{c}}$ of $7.534 \times 10^{-8}$ in reference [20]. Here we assume that Equations (39) and (40) are applicable for H-SOFC as well as $\mathrm{O}-\mathrm{SFOC}$.

$$
\begin{aligned}
& J_{o, a}=k_{a} \frac{72 Y\left[D_{P}-\left(D_{P}+D_{s}\right) n\right] n}{D_{s}^{2} D_{P}^{2}\left(1-\sqrt{1-Y^{2}}\right)} \times\left(\frac{P_{H_{2}}}{P^{0}}\right) \exp \left(-\frac{E_{a c t, a}}{R T}\right) \\
& J_{o, c}=k_{c} \frac{72 Y\left[D_{P}-\left(D_{P}+D_{s}\right) n\right] n}{D_{s}^{2} D_{P}^{2}\left(1-\sqrt{1-Y^{2}}\right)} \times\left(\frac{P_{H_{2} O} O}{P^{0}}\right)\left(\frac{P_{H_{2} O}}{P^{0}}\right)^{0.25} \exp \left(-\frac{E_{a c t, c}}{R T}\right)
\end{aligned}
$$

\subsubsection{Ohmic Loss}

The flow of electrons and ions in fuel cell components results in ohmic polarization due to ohmic resistance in all the layers as well as electrical contact resistance [21] between layers. In order to have a precise ohmic loss analysis, an equivalent electrical circuit for a flow channel and its two walls (local current collectors) was constructed as shown in Figure 2. There are five layers in the electrode assembly. Electrode layers for both anode and cathode are porous material for reactants to diffuse through. Another layer is functional layer where electrochemical reaction takes place. Having functional layer is the recent technology that can enhance the electrochemical reaction by creating more morphological contact between electrode material and electrolyte material. The temperature of functional layer is slight higher than other layers due to exothermic reaction. The current conduction route from a typical anode-side current collector to a cathode-side current collector can be discretized into multiple segments. With the symmetric discretization of the flow channel, computational time for the circuit can be significantly reduced. The electrical potentials at all the nodes are calculated using Kirchhoff's current law, which states that the summation of current flow into the node should be zero. A similar method has been applied to calculate the ohmic loss in PEM fuel cells and O-SOFC [22-24].

The electromotive force shown in the equivalent circuit should be obtained from Equation (3) which also subtracts the activation polarizations of both anode and cathode. The species partial pressures obtained from the mass transfer analysis are used in Equation (3). 
Figure 2. Equivalent electrical circuit for an H-SOFC.

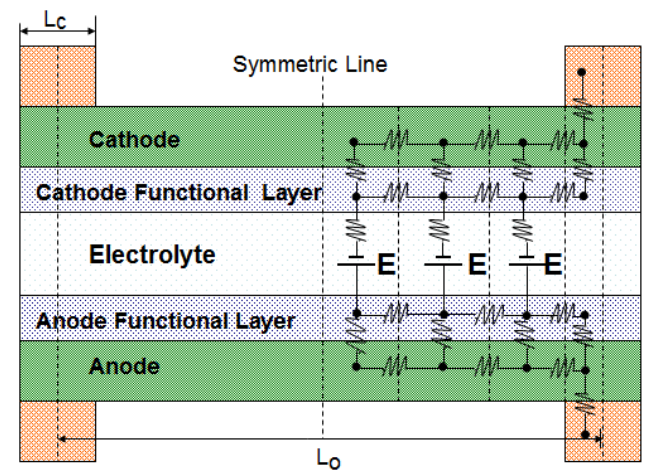

\subsection{Computational Procedures}

The numerical calculation follows a particular procedure, which is outlined as a flow chart in Figure 3. First, all the physical properties and dimensions of the fuel cell are defined. With the known amount of reactants as well as the prescribed current density, the values of concentrations of species at intermediate layers were calculated through iterations of the equations for the mass transfer, which consequently converges. Using these values of concentration, the partial pressures of all species can be calculated which thus considers the concentration polarization in the electromotive force as given in Equation (3). The electrical circuit was then analyzed for ohmic losses by discretizing the single channel fuel cell structure with multiple nodes. The electromotive force shown in the electrical circuit is the value from Equation (3) subtracted with the activation polarization. The activation polarization was considered through Volmer-Butler's equation. From the solution of electrical circuit, the fuel cell voltage is obtained with the given current density and other conditions. Multiple calculations are conducted for a specific temperature and a range of current densities for the $V$ - $i$ curve. The power output from the fuel cell is easily obtained as the product of cell voltage and current, and therefore, the power density versus current density is also obtained for the fuel cell.

Figure 3. Computational procedures for simulation of proton-conductive solid oxide fuel cells.

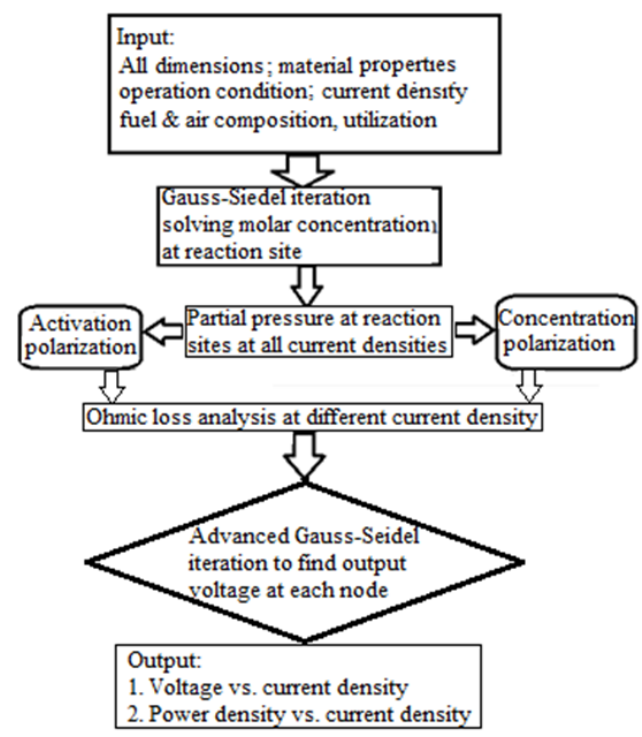




\section{Results and Discussion}

\subsection{Validation to the Modeling}

The analytical modeling is validated by comparing the simulation results with experimental data in literature. The cited experimental results are from references [15]. The studies in the reference reported operation temperatures of the $\mathrm{H}-\mathrm{SOFC}$ up to $700^{\circ} \mathrm{C}$.

Material properties of the H-SOFC from reference [15] are listed in Tables 4 and 5, which were used in the modeling simulation. The tortuosities used for simulation are properly assumed for H-SOFC electrodes. The conductivity of electrode changes with temperature insignificantly compared to that of electrolyte, therefore, it is treated as a constant, as given in Table 5. Current simulation model has a flow channels with width of $1.2 \mathrm{~mm}$ and rib width $0.6 \mathrm{~mm}$ for both anode and cathode channels. The present simulation results of V-I curves are compared with the experimental results from reference [15], as given in Figure 4. The simulation results agree with the experimental data very well, which indicates the validity of the model as well as the related physical properties of the fuel cell components from the literature. The contact resistances at interface at different operation temperatures are shown in Table 3.

Table 4. Material properties from reference [15] used for the present validation of the model.

\begin{tabular}{cccccc}
\hline Material & Thickness & Tortuosity & Porosity & Pore diameter & Grain size \\
\hline Anode $(\mathrm{NiO}+\mathrm{BCY})$ & $600 \mu \mathrm{m}$ & 3 & $48 \%$ & $1-2 \mu \mathrm{m}$ & $2 \mu \mathrm{m}$ \\
Electrolyte $(\mathrm{BCY})$ & $50 \mu \mathrm{m}$ & 3 & $<3 \%$ & - & $2 \mu \mathrm{m}$ \\
Cathode $(\mathrm{BSCF})$ & $20 \mu \mathrm{m}$ & 3 & $48 \%$ & $1-2 \mu \mathrm{m}$ & $2 \mu \mathrm{m}$ \\
\hline
\end{tabular}

Table 5. Conductivities of electrode and electrolyte at different temperatures.

\begin{tabular}{cccc}
\hline $\begin{array}{c}\text { Operating } \\
\text { Temperatures } \\
\left({ }^{\circ} \mathbf{C}\right)\end{array}$ & $\begin{array}{c}\text { Anode } \\
\text { conductivity } \\
(\mathbf{S} / \mathbf{c m})\end{array}$ & $\begin{array}{c}\text { Electrolyte } \\
\text { Conductivity } \\
(\mathbf{S} / \mathbf{m})\end{array}$ & $\begin{array}{c}\text { Cathode } \\
\text { Conductivity } \\
\mathbf{( S / c m )}\end{array}$ \\
\hline 500 & 1400 & 0.67 & 1100 \\
550 & 1400 & 0.77 & 1100 \\
600 & 1400 & 0.95 & 1100 \\
650 & 1400 & 1.12 & 1100 \\
700 & 1400 & 1.38 & 1100 \\
\hline
\end{tabular}

The comparison of the modeling results with experimental data from references has evident that the currently developed H-SOFC model is effective and reliable. In the following section the model will be used to optimize the geometrical designs of the flow channels in H-SOFC. 
Figure 4. Comparison of present modeling results with experimental data in the reference [15]. (a) Operation temperature varies from $500{ }^{\circ} \mathrm{C}$ to $600{ }^{\circ} \mathrm{C}$; (b) Operation temperature varies from $650{ }^{\circ} \mathrm{C}$ to $700{ }^{\circ} \mathrm{C}$.

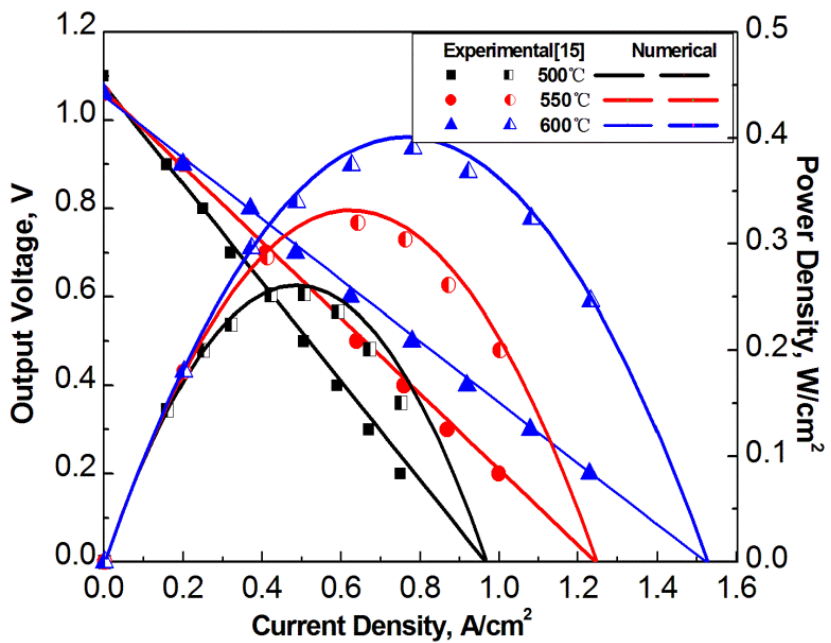

(a)

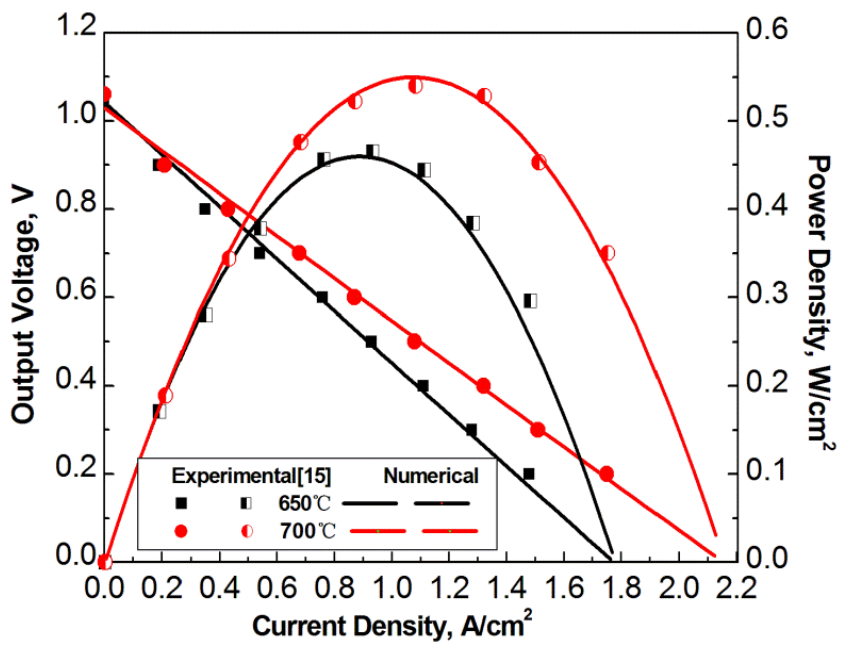

(b)

\subsection{Optimization of the Dimensions of Flow Channels and Walls of an H-SOFC}

A quite number of researchers have reported studies to flow channel and flow field designs, which have been recognized to affect the fuel cell performance in both PEM fuel cells [25] and SOFCs. For PEM fuel cells, it is widely known that serpentine flow channels are known as the "industry standard" due to the better performance compared to that of many other different designs [26]. Serpentine flow channels are commonly adopted in PEM fuel cells [22]. In the present work, serpentine flow channels are considered in the modeling and simulation. The dimensions of flow channels that affect the H-SOFC performance will be optimized. The material property of electrode and electrolyte from Tables 1-3 are used for the simulation.

Two important parameters, the total width $L_{o}$, which includes the width of the flow channel and the width of one of the channel walls, and the ratio of the rib's width versus the total width, are to be optimized for the serpentine flow channels. The rib width is designated as $L c$ and the channel width is $L_{o}-L_{c}$, as seen in Figure 2. The rib ratio $R_{L c}$ is then given as:

$$
R_{L c}=\frac{L_{c}}{L_{o}}
$$

Before the optimization to the flow channel designs, the effect of the operating temperature is studied, and an operating temperature is selected for the optimization of the dimensions of the channels. For this study, the total width is $3 \mathrm{~mm}$ and the rib ratio $R_{L c}$ is 0.3 . The operation temperature ranges from $500{ }^{\circ} \mathrm{C}$ to $700{ }^{\circ} \mathrm{C}$. As seen in Figure 5 the output power density increases with the increase of temperature, which is the same phenomenon as was shown in the model validation simulations and experimental data from literature. High operation temperature makes it possible to have greater reaction kinetics and greater proton conductivity, and also a reduced contact resistance between electrode and current collector, which thus results in higher output voltage. 
Figure 5. Fuel cell output power density versus current density at various operation temperatures. (Total channel width $L_{o}=3 \mathrm{~mm}$; rib ratio $R_{L c}=0.3$ ).

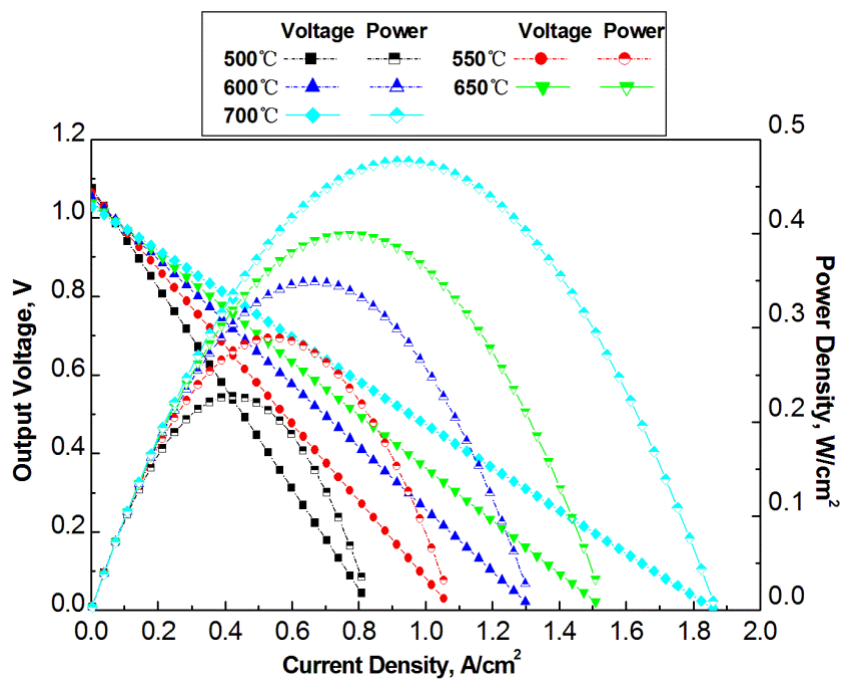

The flow channel geometry optimization simulation is conducted under operation temperature of $700{ }^{\circ} \mathrm{C}$ which allows it to achieve high power density among the simulated temperatures. Three groups of dimensions of channels are selected for optimization design, which have total width $L_{o}$ in $2 \mathrm{~mm}$, $4 \mathrm{~mm}$, and $6 \mathrm{~mm}$, respectively. In each group of dimensions, five rib ratios are selected. Figure 6 presents the power density versus current density of the three groups of cells.

Figure $6 \mathrm{a}-\mathrm{c}$ show a common characteristics that the cell power output increases with the decrease of the rib ratio for the studied cases under a constant total channel width $L_{o}$. The maximum output power density in Figure 6a is around $0.64 \mathrm{~W} / \mathrm{cm}^{2}$ at a rib ratio of $R_{L c}=0.05$, which is $70 \%$ greater than the case with a rib ratio of $R_{L c}=0.5$. Obviously, the smaller rib ratio means more opening area of electrochemical reactions, and therefore, the fuel cell power density increases. On the other hand, with more and more decrease of the rib ratio the increase of the fuel cell power density becomes less significant, which implies that too small rib ratio should not be selected. A small width of the rib also means high contact resistance. It can also be difficult to fabricate the flow channels with very small walls.

At larger total widths, $L_{o}=4 \mathrm{~mm}$, and $6 \mathrm{~mm}$, the decrease of the rib ratio also results in the increase of the fuel cell power density. However, the maximum power densities from the three cases of different total widths are different. With smaller total width, the maximum power density is higher than that with larger total width. The maximum power density in Figure $6 \mathrm{a}-\mathrm{c}$ is $0.64 \mathrm{~W} / \mathrm{cm}^{2}, 0.6 \mathrm{~W} / \mathrm{cm}^{2}$ and $0.58 \mathrm{~W} / \mathrm{cm}^{2}$, respectively.

To have an overview of the optimization of flow channels, Figure 7 shows the effect of rib ratio to the maximum power density at different operation temperatures, ranging from $500{ }^{\circ} \mathrm{C}$ to $700{ }^{\circ} \mathrm{C}$. The selected another three cases of channel total widths are $1.5 \mathrm{~mm}, 3.0 \mathrm{~mm}$, and $4.5 \mathrm{~mm}$. The rib ratio in each case varies from 0.01 to 0.3 .

It is seen from Figure 7 that at all the studied temperatures, the decrease of the rib ratio is preferable, which results in the increase of the maximum power density. At different operation temperatures, the optimum rib ratio can be slightly different. For example, at temperature of $500{ }^{\circ} \mathrm{C}$, the optimum rib ratio is around 0.1 , while at temperature of $700{ }^{\circ} \mathrm{C}$ the optimum rib ratio is smaller. Nevertheless, nearly one 
optimum rib ratio can be largely applicable to all the different operation temperatures, for example, a rib ratio of 0.05 , in all the studied cases.

Figure 6. Cell voltage and power density versus current density at cell temperature of $700{ }^{\circ} \mathrm{C}$. (a) $L_{o}=2 \mathrm{~mm}$; (b) $L_{o}=4 \mathrm{~mm}$; (c) $L_{o}=6 \mathrm{~mm}$.

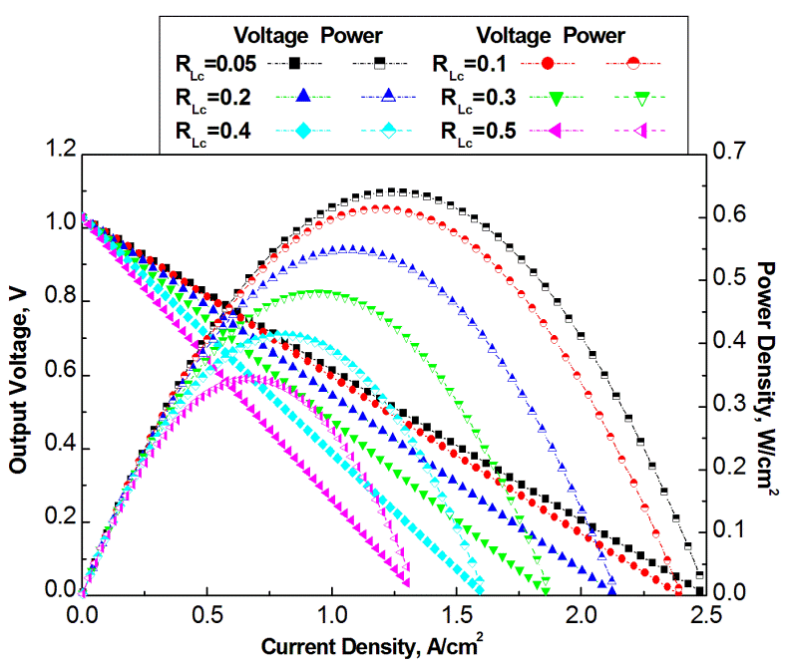

(a)

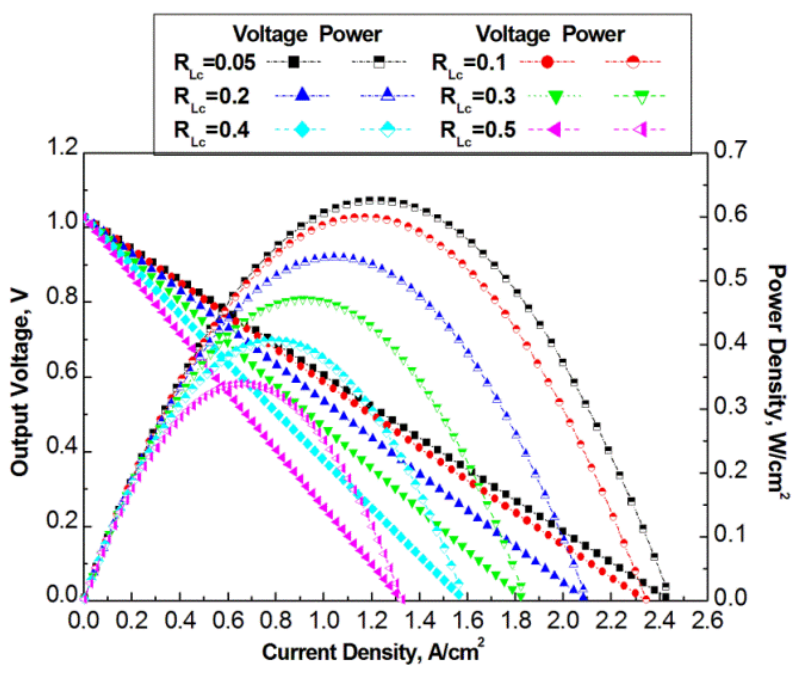

(b)

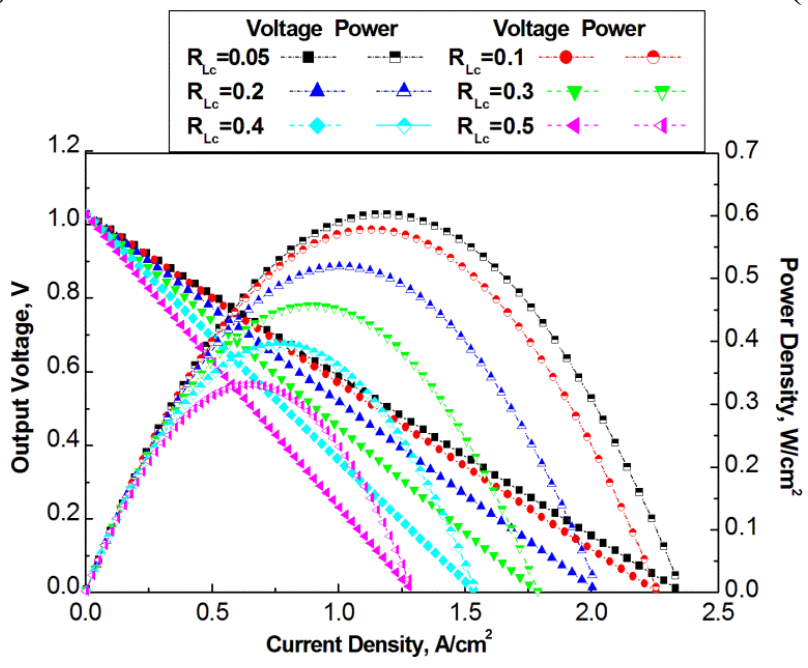

(c)

To show the overview of the effect of both the total width $L_{o}$ and the rib ratio $R_{L c}$, Figure 8 presents a contour of the maximum power density as a function of the total width and rib ratio. It is clear that the peak of the maximum power density locates at the coordinate of both small total width and small rib ratio. For a fixed total width (summation of channel width and rib width), the increase of $R_{L c}$ means that channel rib area increases which will tend to improve the current collection efficiency. However, increase of $R_{L c}$ results in the decrease of channel flow area, which does not benefit to improvement of the cell power density. This is because that decrease of channel area will decrease the exposure of reactants to electrode layer and reduce the diffusion and reaction, which will result in the drop of power density. It is also found that the maximum power density from fuel cells is more sensitive to the variation of the rib ratio rather than the total channel width. The channel and rib width affect the performance of proton conducting SOFCs and it also has effect on conventional SOFCs and other type of fuel cells [13]. 
Figure 7. The maximum power densities obtained at channel designs with different rib ratios and different operation temperatures. (a) $L_{o}=1.5 \mathrm{~mm}$; (b) $L_{o}=3.0 \mathrm{~mm}$; (c) $L_{o}=4.5 \mathrm{~mm}$.

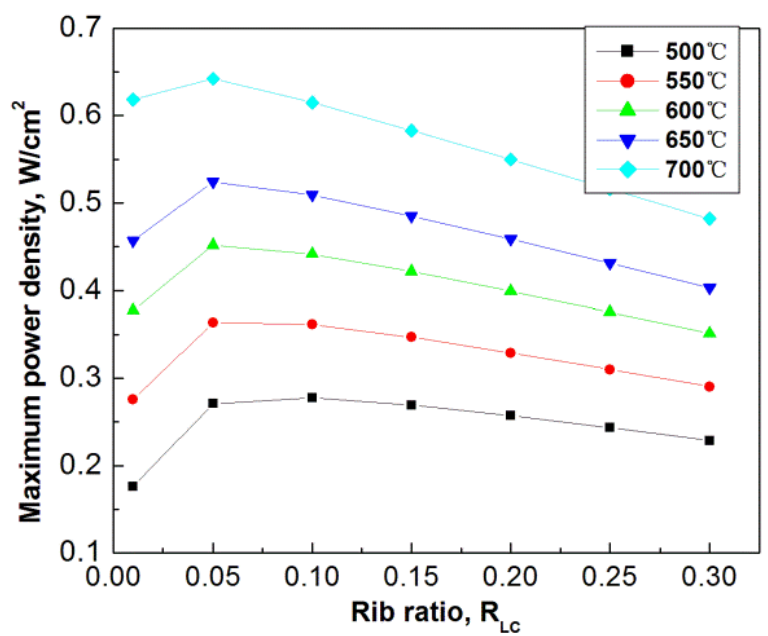

(a)

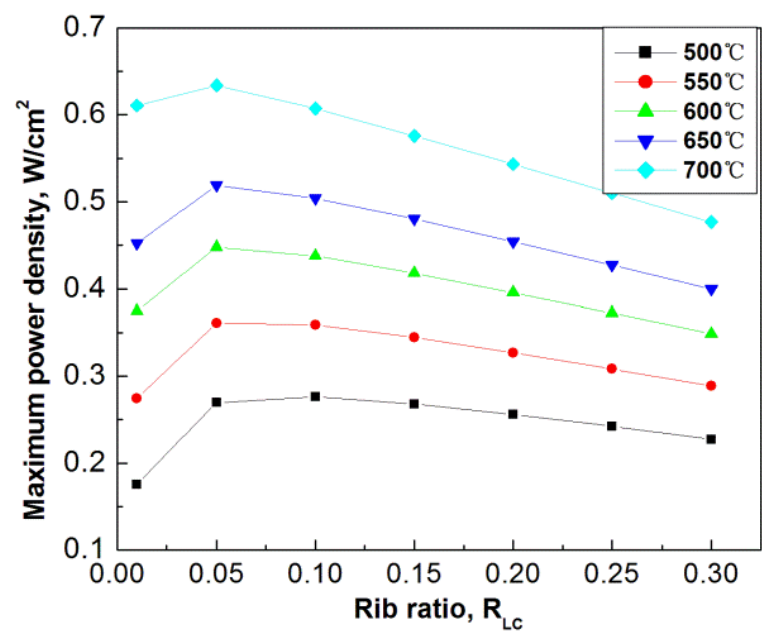

(b)

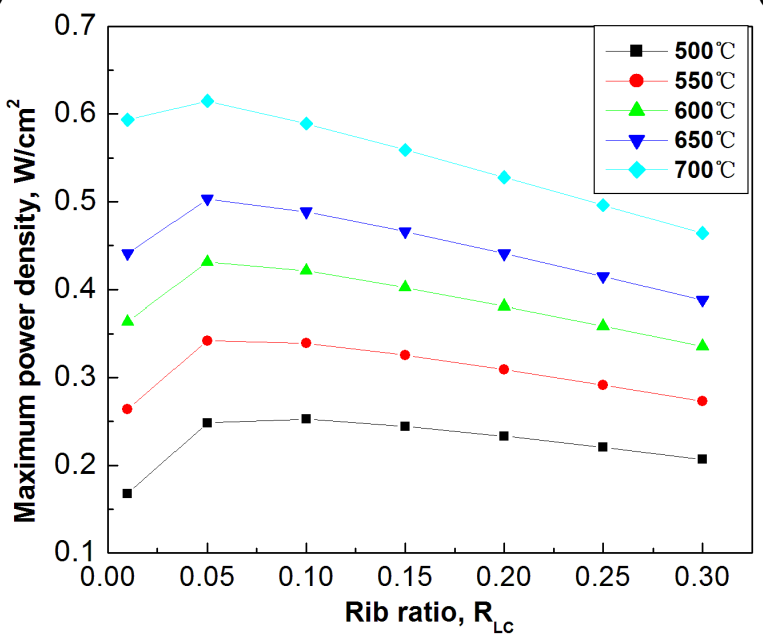

(c)

Figure 8. H-SOFC maximum power density in variation with the designs of total channel width and rib ratio (a) Operation temperature of $500^{\circ} \mathrm{C}$; (b) Operation temperature of $700{ }^{\circ} \mathrm{C}$.

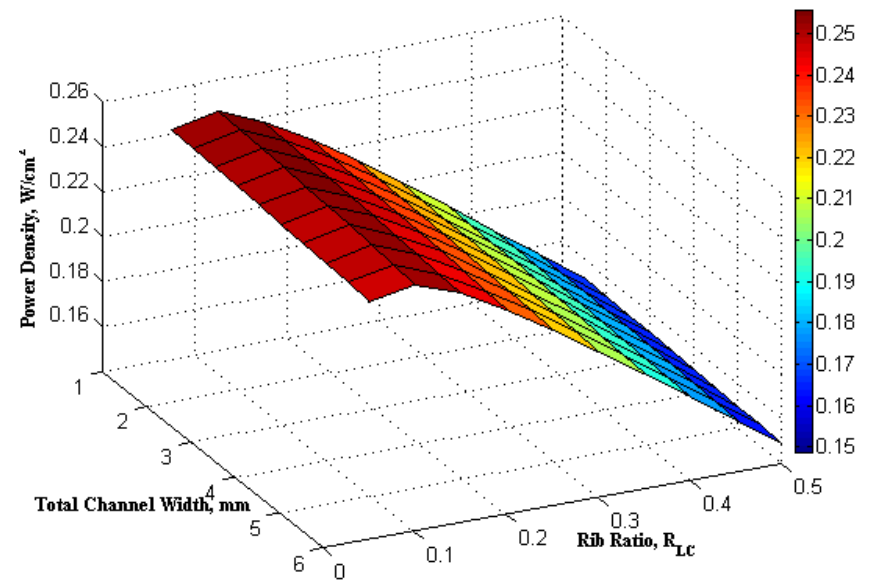

(a)

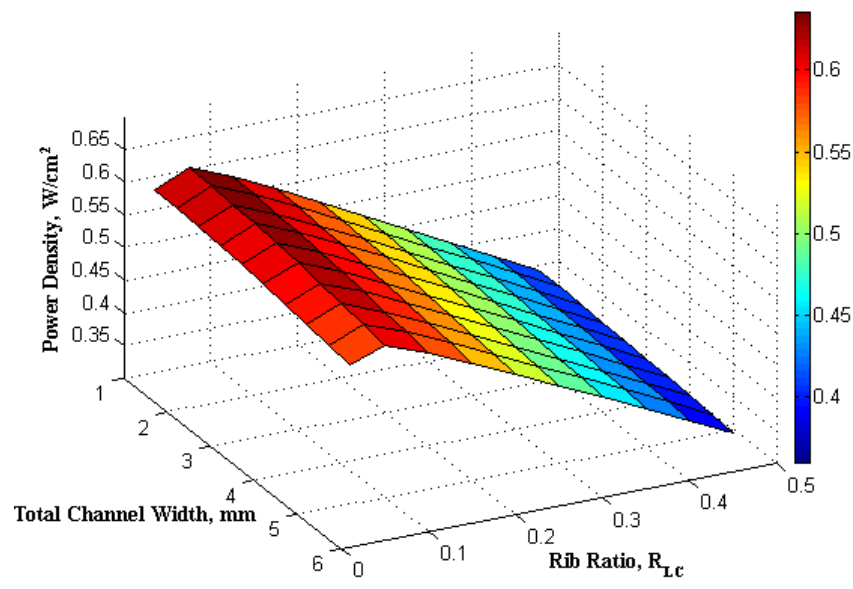

(b) 


\section{Conclusions}

An analytical model was developed for an H-SOFC in order to study the fuel cell performance and also to optimize the flow channel designs. This is a one-dimensional model that was validated by experimental data from the literature and was used to simulate and optimize the flow channel dimensions, mainly two important parameters - the total width of flow channel with channel rib/wall and the ratio of the channel rib/wall to the total width.

It was found from the optimization study that the fuel cell maximum power density can be higher if one chooses a smaller total width as well as a smaller ratio of the width of channel rib/wall against the total width. However, this ratio has an optimum point, too small a value can also result in decrease of the maximum power density. To show this feature, a contour of the maximum power density as a function of the total width and the rib ratio is provided in the paper.

The optimum ratio of channel rib/wall versus the total width varies slightly with the difference of the operation temperature. Nevertheless, nearly one optimum rib ratio can be largely applicable to all the different operation temperatures.

\section{Acknowledgments}

The support from the Office of Naval Research of the USA and the University of Tennessee SimCenter under the contract \#8500011366 is gratefully acknowledged.

\section{Conflicts of interest}

The authors declare no conflict of interest.

\section{References}

1. Ni, M.; Leung, D.Y.C.; Leung, M.K.H. Mathematical modeling of ammonia-fed solid oxide fuel cells with different electrolytes. Int. J. Hydrog. Energy 2008, 33, 5765-5772.

2. Hajimolana, S.A.; Hussain, M.A.; Ashri Wan Daud, W.M.; Soroushb, M.; Shamiri, A. Mathematical modeling of solid oxide fuel cells: A review. Renew. Sustain. Energy Rev. 2011, 15, 1893-1917.

3. Iwahara, H. Proton conducting ceramics and their applications. Solid State Ion. 1996, 86-88, 9-15.

4. Pen, R.; Wu, Y.; Yang, L.; Mao, Z. Electrochemical properties of intermediate-temperature SOFCs based on proton conducting Sm-doped BaceO3 electrolyte thin film. Solid State Ion. 2005, 177, 389-390.

5. Zhao, F.; Chen, F. Performance of solid oxide fuel cells based on proton-conducting $\mathrm{BaCe}_{0.7} \mathrm{In}_{0.3-\mathrm{x}} \mathrm{Y}_{\mathrm{x}} \mathrm{O}_{3-\delta}$ electrolyte. Int. J. Hydrog. Energy 2010, 35, 11194-11199.

6. Ling, Y.; Chen, J.; Wang, Z.; Xia, C.; Peng, R.; Lu, Y. New ionic diffusion strategy to fabricate proton-conducting solid oxide fuel cells based on a stable $\mathrm{La}_{2} \mathrm{Ce}_{2} \mathrm{O}_{7}$ electrolyte. Int. J. Hydrog. Energy 2013, 38, 7430-7434.

7. Guo, Y.; Ran, R.; Shao, Z. Fabrication and performance of a carbon dioxide-tolerant proton-conducting solid oxide fuel cells with a dual-layer electrolyte. Int. J. Hydrog. Energy 2010, 35, 10513-10521.

8. Sun, W.; Zhu, Z.; Shi, Z.; Liu, W. Chemically stable and easily sintered high temperature proton conductor $\mathrm{BaZr}_{0.8} \mathrm{In}_{0.2} \mathrm{O}_{3-\delta}$ for solid oxide fuel cells. J. Power Source 2013, 229, 95-101. 
9. Lin, Y.; Zhou, W.; Sunarso, J.; Ran, R.; Shao, Z. Characterization and evaluation of $\mathrm{BaCo}_{0.7} \mathrm{Fe}_{0.2} \mathrm{Nb}_{0.1} \mathrm{O}_{3-\delta}$ as a cathode for proton-conducting solid oxide fuel cells. Int. J. Hydrog. Energy 2012, 37, 484-497.

10. Ding, H.; Xue, X. Proton conducting solid oxide fuel cells with layered $\operatorname{PrBa}_{0.5} \mathrm{Sr}_{0.5} \mathrm{Co}_{2} \mathrm{O}_{5-\delta}$ perovskite cathode. Int. J. Hydrog. Energy 2010, 35, 2486-2490.

11. Zhao, L.; He, B.; Ling, Y.; Xun, Z.; Peng, R.; Meng, G.; Liu, X. Cobalt-free oxide $\mathrm{Ba}_{0.5} \mathrm{Sr}_{0.5} \mathrm{Fe}_{0.8} \mathrm{Cu}_{0.2} \mathrm{O}_{3-\delta}$ for proton-conducting solid oxide fuel cell cathode. Int. J. Hydrog. Energy 2010, 35, 3769-3774.

12. Tsai, C.-L.; Schmidt, V.H. Tortuosity in anode-supported proton conductive solid oxide fuel cell found from current flin rates and dusty-gas model. J. Power Sources 2011, 196, 692-699.

13. Li, P.W.; Kotwal, A.; Sepulveda, J.L.; Loutfy, R.O.; Chang, S. An easy-to-approach and comprehensive model for planar type SOFCs. Int. J. Hydrog. Energy 2009, 34, 6393-6406.

14. Ni, M.; Leung, M.K.H.; Leung, D.Y.C. Mathematical modeling of proton-conducting solid oxide fuel cells and comparison with oxygen-ion-conducting counterpart. Fuel Cells 2007, 7, 269-278.

15. Lin, Y.; Ran, R.; Zheng, Y. Evaluation of $\mathrm{Ba}_{0.5} \mathrm{Sr}_{0.5} \mathrm{Co}_{0.8} \mathrm{Fe}_{0.2} \mathrm{O}_{3-\delta}$ as a potential cathode for an anode-supported proton-conducting solid-oxide fuel cell. J. Power Sources 2008, 180, 15-22.

16. Deng, X.; Petric, A. Geometrical modeling of the triple-phase-boundary in solid oxide fuel cells. J. Power Sources 2005, 140, 297-303.

17. Lin, B.; Hu, M.; Ma, J.; Jiang, Y.; Tao, S.; Meng, G. Stable, easily sintered $\mathrm{BaCe}_{0.5} \mathrm{Zr}_{0.3} \mathrm{Y}_{0.16} \mathrm{Zn}_{0.04} \mathrm{O}_{3-\boldsymbol{\delta}}$ electrolyte-based protonic ceramic membrane fuel cells with $\mathrm{Ba}_{0.5} \mathrm{Sr}_{0.5} \mathrm{Zn}_{0.2} \mathrm{Fe}_{0.8} \mathrm{O}_{3-\delta}$ perovskite cathode. J. Power Sources 2008, 183, 479-484.

18. Fuller, E.N.; Schettler, P.D.; Giddings, J.C. New methods for prediction of binary gas-phase diffusion coefficients. Ind. Eng. Chem. Res. 1966, 58, 18-27.

19. Loius, C. Burmeister Convection Heat Transfer, 2nd ed.; John Wiley \& Sons, Inc.: New York, NY, USA, 1993; Chapter 2, pp. 38-39.

20. Ni, M.; Leung, M.K.H.; Leung, D.Y.C. Parametric study of solid oxide fuel cell performance. Energy Convers. Manag. 2007, 48, 1525-1535.

21. Kraytsberg, A.; Auinat, M.; Ein-Eli, Y. Reduced contact resistance of PEM fuel cell's bipolar plates via surface texturing. J. Power Sources 2007, 164, 697-703.

22. Liu, H.; Li, P.; Wang, K. Optimization of PEM fuel cell flow channel dimensions-Mathematic modeling analysis and experimental verification. Int. J. Hydrog. Energy 2013, 38, 9835-9846.

23. Li, P.; Ki, J.-P.; Liu, H. Analysis and optimization of current collecting systems in PEM fuel cells. Int. J. Energy Environ. Eng. 2012, 3, 1-10.

24. Li, P.; Tao, G.; Liu, H. Effect of the geometries of current collectors on the power density in a solid oxide fuel cell. Int. J. Energy Environ. Eng. 2011, 2, 1-11.

25. Aiyejina, A.; Sastry, M.K.S. PEMFC flow channel geometry optimization: A review. J. Fuel Cell Sci. Technol. 2012, 9, 011011:1-011011:24.

26. Li, X.; Sbir, I.; Park, J. A flow channel design procedure for PEM fuel cells with effective water removal. J. Power Sources 2007, 163, 933-942.

(C) 2014 by the authors; licensee MDPI, Basel, Switzerland. This article is an open access article distributed under the terms and conditions of the Creative Commons Attribution license (http://creativecommons.org/licenses/by/3.0/). 